\title{
¿QUIÉN NECESITA IMÁGENES? NOTAS SOBRE LA ANSIEDAD ETNOGRÁFICA
}

Carlos Masotta ${ }^{12}$

Aproximadamente quince años atrás me encontraba realizando trabajo de campo en una comunidad del pueblo qom (tobas) en la provincia de Chaco (Argentina) cuando se desarrolló un pequeño evento que desde entonces he adoptado como una buena lección en torno a la relación de la etnografía con el relevamiento visual.

El objetivo de la investigación era la realización de un documental para el Instituto Nacional de Antropología sobre la historia de inmigración de ese pueblo indígena hacia Buenos Aires. Nos presentamos ante los jefes de la comunidad y explicamos que nos encontrábamos allí con ese fin. Quise tomar algunas fotografías del lugar, pero el poco tiempo de estadía volvía esta práctica un poco intempestiva, es decir, con la carga de violencia que cualquiera puede sentir al ser fotografiado por un desconocido o recién llegado. Con todo, y contando con el permiso del dirigente de la comunidad, comencé con esa terea antes que oscureciera. Recuerdo la tensión que se producía sobre mi espalda mientras enfocaba la cámara en el paisaje y en algunos rostros. Estaba traicionando una de las reglas básicas de cualquier manual actual de etnografía que consiste en no confundir al antropólogo con un curioso impertinente. Pero al mismo tiempo las condiciones de la luz y el entorno se mostraban tan óptimas para la imagen y sucumbí ante esto. Ya había avanzado la tarde y el sol se acercaba al horizonte iluminando los rostros, las casas, acentuando el verde de los árboles y el dorado del campo circundante afectado por la falta de agua. Las cámaras digitales aun no se habían divulgado y trabajaba con una analógica con película. A diferencia de las primeras no era posible chequear en el momento los resultados de la toma y la tarea de registro era más concentrada y atenta. Por el calor imperante, las familias y los vecinos se reunían en pequeños grupos frente a sus casas y así mi actividad se realizaba ante la vista de todos.

Unos minutos después un hombre se separó de un grupo y sosteniendo una pequeña cámara fotográfica se dirigió hacia mí. Cuando estuvimos frente a frente, enfocó su

\footnotetext{
${ }^{1}$ Universidad de Buenos Aires, Argentina.

2 Doctor en Antropología (UBA- CONICET- Instituto Nacional de Antropologia y Pensamiento Latinoamericano).
} 
máquina en mi rostro y comenzó a disparar insistentemente accionando el flash. Mientras hacía esto reía y sus amigos desde lejos le gritaban festejando el evento. Uno de ellos, al ver la repetición de los disparos, le advirtió: “¡te vas a quedar sin rollo (película)!” a lo que el hombre contestó “¡no importa, no tiene rollo!”.

Reflexionando sobre lo sucedido, la parodia se me mostró doble. Por un lado imitaba burlescamente al antropólogo impertinente pero también, con la intervención de una cámara inútil, esa crítica avanzaba sobre la misma práctica fotográfica, con una cámara sin película.

Lo que parecía estar en juego, era un problema de tiempos. El humor desplegaba una representación invertida al respecto: un investigador inoportuno y una práctica inútil. Se suele considerar que tanto la presencia del antropólogo en el campo como sus tomas fotográficas no son acciones resueltas en sí mismas, sino que se justifican en relación a lo que con posterioridad se hará con ellas. Pero la parodia desbarataba esa forma de planificación y, exagerando la compulsión al registro con una tecnología vacía, mostraba que todo se resolvía allí y que así, sin plan futuro, se volvía fuente de ridículo.

En el trabajo de campo, la fotografía (al igual que el registro fílmico) interviene como un evaluador en su temporalidad pues, en la identificación de la ocasión pertinente para el registro, suele empujar al antropólogo contra sus bordes. La fotografía se expresa entonces con todo su peso como dispositivo social pues en su ejecución, coincide la consideración de las relaciones interpersonales del investigador con sus informantes a la vez que la disposición temporal de su estadía en el campo. Por ejemplo, la documentación visual de un ritual es sin duda relevante pero, ¿en qué momento es pertinente?, ¿Tendré otra oportunidad de fotografiarlo?", para la comunidad local ¿es un evento fotografiable?, de no ser así ¿cuento con las autorizaciones necesarias para hacerlo? Gravita sobre el trabajo de campo una ideología de la oportunidad, maximización del tiempo, y control del azar que suele exponer las ansias del antropólogo, o por lo menos colocarlo de cara a ellas.

Desde entonces he trabajo relacionando la antropología con el mundo de las imágenes. Por un lado he investigado sobre las formas de representación fotográfica de pueblos indígenas en diferentes casos históricos. Por el otro he recurrido al video y a la fotografía como herramienta en el trabajo de campo. Con estas aplicaciones realicé numerosos documentales y cortos etnográficos para uso académico y de divulgación. A lo 
largo de estas experiencias he reparado en situaciones que remitían reflexivamente a la relación intercultural operada a través de la inclusión de imágenes y del registro visual. En las presentes notas tomaré algunas de esas situaciones para comentar el lugar de las imágenes en el trabajo de campo y el problema de dialogicidad en etnografía.

\section{El trabajo de campo como cámara oscura}

Poco antes del fin del siglo XX aun era común el uso de cámaras fotográficas analógicas en el trabajo de campo. Comparados con los actuales dispositivos digitales, el número de tomas de aquellas cámaras era muy acotado y sus productos algo misteriosos pues revelaban su poder solo después, cuando las imágenes se hacían visibles en el papel. Ese registro, en relación al tiempo retardado de su confirmación en la copia, estaba atravesado por cierto sentimiento de impaciencia y ansiedad. Desde la toma hasta el papel, el acto fotográfico cruzaba la frontera del trabajo de campo junto al antropólogo que observaría pos facto el resultado de su registro. Ya en la metrópoli, esas imágenes le recordaban la experiencia pasada en la aldea a la vez que lo afirmarían en su devenir como investigador. Además, en la etnografía de sociedades indígenas (los llamados pueblos primitivos) los efectos temporales de la fotografía se multiplicaban en torno al contraste entre la modernidad de esa técnica y el primitivismo adjudicado a quienes eran por ella retratados.

El uso de imágenes en antropología además de una fuente o herramienta de registro y difusión de conocimiento es un singular dispositivo productor de temporalidad de sus discursos y al interior mismo de la misma disciplina.

En sus clases de técnicas etnográficas, Marcel Griaule recomendaba tanto la toma sistemática de fotografías como el revelado in situ. De no ser posible esto último, se deberían enviar los negativos a la metrópoli y recibir las fotografías lo más rápido posible. El paso del tiempo atentaba contra la sistematización de las imágenes pues a mayor distancia del momento de la toma se hacía más difícil reponer su información contextual. Ellas se deberían ordenar en relación al diario de campo con fichas descriptivas de los lugares, personas, acciones y objetos registrados. Para entonces, se hizo evidente que la escritura no podía traducir todo el conocimiento cultural y que la fotografía (y el film) por 
su poder de descripción realista y automática podían ser un aliado ideal para saldar esa falta.

El recurso a la fotografía etnográfica (presente ya en los orígenes mismos de la disciplina) delata los deseos por la producción de una duplicación textual. Pero la producción de un doble textual o analogón conlleva al sujeto observado hacia la pregunta sobre sus intenciones. Más aun cuando la imagen registra al individuo, a sus signos o a los de su comunidad. La impertinencia del antropólogo se vuelve entonces evidente. Algo de esto comentaba Evans Pritchard (1977) al señalar las dificultades de obtención de información entre los nuer: "Bloqueaban las preguntas sobre sus costumbres con una técnica que puedo recomendar a los nativos que se sientan inportunados por la curiosidad de los etnólogos".

$(\ldots)$

E-P: Como te llamas?

Cuol: Quieres saber mi nombre?

E-P: $\mathrm{Si}$

Cual: de verdad quieres saber mi nombre?

E-P: Si, has venido a visitarme a mi tienda y me gustaría saber quien eres.

Cuol: De acuerdo, soy Cuol. Cómo te llamas tu?

$(\ldots)$

E-P: Como se llama tu linaje?

Cuol: quieres saber el nombre de mi linaje?

E-P: $\mathrm{Si}$

Cuol: Que harás si te lo digo, te lo llevaras a tu tierra?

E-P: No quiero hacer nada con él. Simplemente quiero conocerlo pues estoy viviendo en tu campamento.

$(\ldots)$

Cuol: porqué quieres saber el nombre de mi linaje?

E-P: no quiero saberlo"

(Evans-Pritchard, 1977: 25)

Por supuesto el nombre del linaje no es igual a una fotografía, pero para nuestro problema parecen operar en direcciones similares. Basta recordar los usos burgueses del retrato o las fotos de grupos familiares. También los frecuentes ejercicios racistas o esencialistas de las imágenes etnográficas. La creencia indígena de la fotografía como robo del alma, más que una superstición fue la confirmación de sus frecuentes usos y abusos. 
La anécdota, además de describir el juego dialógico por el control de la información me interesa particularmente pues comenta la impaciencia del investigador.

"Desafío al más paciente de los etnólogos a que intente avanzar contra esta clase de oposiciones. Simplemente te vuelves loco. De hecho después de algunas semanas de relacionarme exclusivamente con los nuer, empieza uno a mostrar, (...) los síntomas más evidentes de nuerosis." (Evans-Pritchard, 1977: 25). ${ }^{3}$

Existe una foto de la misma época del dialogo de Evans Pritchad que confirma los consejos de Marcel Griaule. En ella se lo ve durante la campaña Dakar-Djibuti sentado en el interior de una carpa negra sosteniendo un negativo que observa inmutable y expectante. La carpa no es la típica tienda del antropólogo en la aldea, sino un cuarto oscuro móvil que ha sido montado en el interior de una casa dogón de adobe. Como un telón que se ha corrido muestra en su interior al hombre en ese acto casi mágico que consistía en revelar fotografías. Se trata de una foto imposible pues para la toma el cuarto oscuro fue abierto violando su imprescindible penumbra para su función. La puesta en escena delata un interés, no solo por retratar al antropólogo en el trabajo de campo (o junto a sus nativos, como fue el caso de muchas fotos en las que Malinowski se retratara en las islas Trobriand), sino en ese acto especial de revelar en tierra dogon algo de ese mismo mundo.

${ }^{3}$ Sobre este diálogo puede consultarse Rosaldo (1986). 


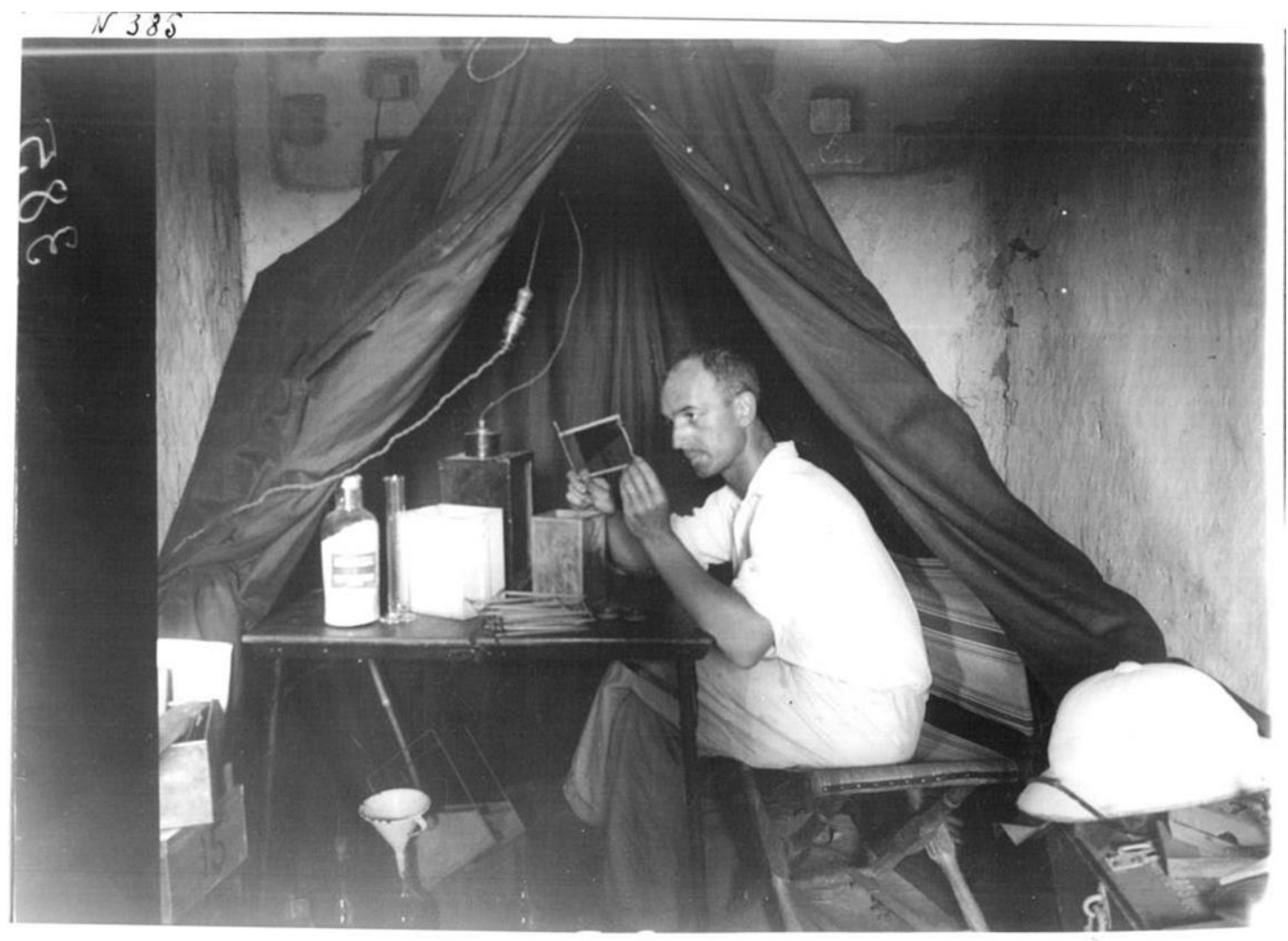

1. Marcel Griaule, Campaña Dakar-Djibouti. Fonte: Revista Domus.

Pero, lo importante en este caso no es lo que allí se revela sino que ese acto se realice en esa locación. Si la foto de Griaule lo mostrara en un laboratorio en París no tendría el mismo valor. Insisto en este punto, pues tal vez, esa imagen muestre algo más que una operación de autoridad donde el investigador confirma el haber "estado allí" (Geertz, 1989).

La carpa negra de Griaule dentro de la casa dogon se parece también a una metáfora del trabajo de campo como cámara oscura, como un lugar abierto por el antropólogo en el espacio cultural para que allí se revele, por su intermedio experto, el conocimiento sobre el pueblo o las prácticas estudiadas. La escena es paradójica pues muestra al investigador a la vez dentro (en la casa dogon) y fuera del campo (solo, casi oculto en su tienda). Algo similar a lo que ocurría con las cámaras oscuras que se usaron desde el siglo XVII. Se trataba de un compartimento donde el dibujante podía introducirse para copiar la imagen 
del paisaje del entorno que se reflejada, a través de un orificio, en una de sus paredes y gracias a un efecto lumínico. Poco antes del 1700 el inglés Robert Hooke ideó un modelo portátil parecido a una gran escafandra en el que se introducía la cabeza. Ya en el siglo XIX los naturalistas y viajeros usaron equipos más livianos similares a la carpa de la foto de Griaule.

Como se sabe, la mediación de la tecnología tiene una estrecha relación con el positivismo y la producción del conocimiento científico. En el desarrollo de la parafernalia óptica descansa la ideología de la verdad de la imagen. Pero la carpa de Griaule no es exactamente una cámara oscura sino un laboratorio de revelado. Su desplazamiento de la metrópoli recuerda al viajero del siglo XIX, pero su pose expectante, su cuerpo y mirada, volcados sobre el negativo de la fotografía evocan al erudito hurgando la realidad en sus textos. Si no se tratara de un alarde tecnológico en tierras primitivas podría verse como un acto surrealista. En verdad, un retrato del aislamiento etnográfico, una de las ficciones fundadoras de la escritura antropológica.

La puesta en escena de Griaule en su cuarto oscuro, esa mezcla de aislamiento, pose expectante y revelación, puede verse como una anticipación de la experiencia iniciática que marcaría posteriormente su investigación. En efecto, en 1947 el antropólogo fue iniciado por el sabio dogon Ogotemmeli en los secretos culturales de su pueblo (un análisis en Clifford, $\left.1988^{4}\right)$.

\section{Régimen digital y alternativas dialógicas}

La compaginación de capítulos de la historia de la fotografía con la de la antropología además de describir la contemporaneidad e intersecciones de ambos desarrollos, se ofrece como una reflexión sobre los marcos epistemológicos de esta última y los regímenes de imágenes imperantes (ver Pinney, 1991). Así, tal vez no sea solo coincidencia que los problemas de la escritura y del trabajo de campo en una perspectiva dialógica (Clifford y Marcus 1986; Clifford, 1988) se divulgaran en coincidencia con el paso de la imagen analógica a la digital.

\footnotetext{
${ }^{4}$ La fotografía comentada fue incluida en el libro de James Clifford (1988). Pero allí la imagen original fue recortada en sus contornos. Solo muestra al invetigador en su carpa y no deja ver que esta se encontraba dentro de la construcción dogon.
} 
Los dispositivos digitales modificaron el tiempo fotográfico propio de la tecnología anterior. Al descartar el proceso de revelado, la producción de imágenes se volvió un acto inmediato, y su chequeo y confirmación un gesto contiguo al de la toma. El cambio ha democratizado en parte al acto fotográfico haciendo frecuentemente de ese gesto un acto grupal entre los involucrados. Al mismo tiempo, la diversificación de aparatos de registro y archivo hacen inmediatas también las formas de circulación y usos en una escala sin precedentes por su alcance y magnitud. En la actualidad las prestadoras de Internet están tan interesadas en el consumo de fotografía y videos como los mismos fabricantes de cámaras. La imagen digital se ha constituido como un complejo toma/revelado/archivo. Actividades que antes operaban en forma independiente y en tiempos diferenciados ahora se resitúan mutuamente y en contigüidad. La difusión y diversidad de aplicaciones no debe ocultar sin embargo la naturaleza del régimen escópico (Jay, 2003) y carácter imperativo que enmarca a estos cambios.

En diferentes situaciones de campo en comunidades indígenas he notado cómo el uso de cámaras digitales (foto o video) tiene un desempeño diferente a las anteriores. Muestran lo que hacen y propician hablar de ello e incluso adaptarse a sugerencias y criterios de los mismos consultantes. Asimismo, modifican a la vez que abren nuevos escenarios, conflictos e interrogantes para la labor antropológica. Ilustraré con dos ejemplos personales en torno al video en situación etnográfica.

En 2004 realicé una entrevista en video a Lino Fernández, un integrante de la comunidad qom de la provincia del Chaco (Argentina). El poseía conocimientos lingüísticos especialmente importantes para el proyecto de investigación que se desarrollaba. Lino participaba como consultante desde hacia un año y conocía sus objetivos y alcances específicamente linguísticos, pero al comenzar la entrevista no habló de esa lengua sino que presentó ante la cámara un detallado relato sobre la represión militar que su comunidad había sufrido en 1924. La información había sido transmitida por su padre quien le había entregado un cartucho de bala de ametralladora recogida en el lugar de esos hechos. Mediando su relato, Lino sacó ese objeto en un bolsillo y lo colocó sobre la mesa delante del objetivo de la cámara. Así se desarrolló una performance de transmisión en la que el informante adoptó al registro de video como un efecto de difusión ampliado. Es 
decir, el padre de Lino entregó a su hijo un relato y un objeto que este transfiere a través del registro visual.

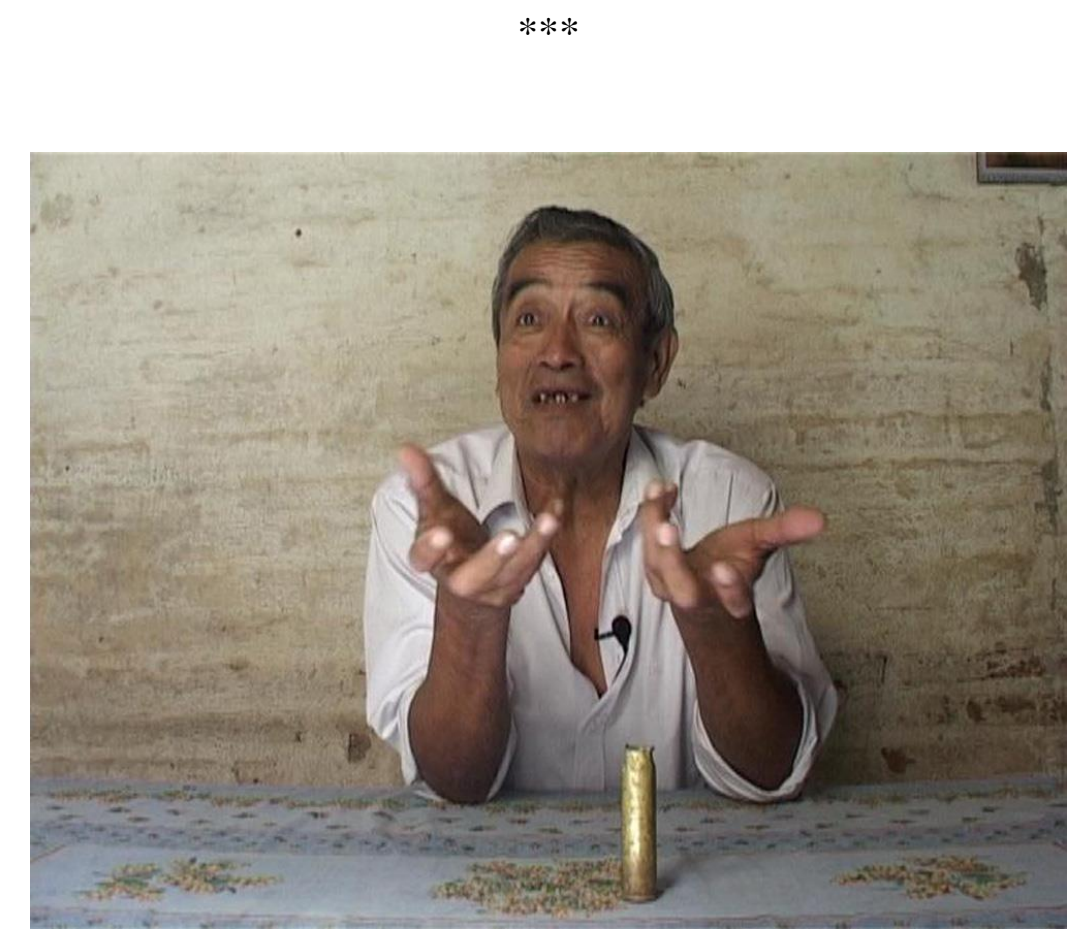

2. Lino Fernández, video La Matanza. Carlos Masotta, Argentina, 2004.

La contundencia del relato (su contenido y su forma) se mostró más relevante que la información lingüística que el proyecto de investigación buscaba. La incorporación del objeto en el desarrollo del relato fue previsto por el consultante con anterioridad a la entrevista y su puesta en escena fue decidida en relación al monitoreo del devenir de ese contexto. El registro en video fue adoptado como un lugar de actuación de la performace narrativa que la instancia de entrevista abierta a su vez posibilitó. En el curso de su alocución, Lino realizó un comentario reflexivo:

"Siempre quise comentarlo..., pero ahora no sé..., tenemos más confianza".

Lo que intento señalar es que en este caso el efecto inhibitorio de la cámara fue reemplazado por una forma de transmisión local que se apropió de la instancia de registro. El relato de "La matanza" como se lo conoce en esa comunidad es transmitido hasta la 
actualidad como un evento singular en términos locales. Pero ahora esa transmisión operaba sobre el antropólogo y se ampliaba con la capacidad de reproducción de ese registro. La autoridad etnográfica fue intervenida por el relato pues este no respondió a las consignas que el proyecto de investigación sugería y además por reponer la denuncia de la represión ejercida por el Estado. Este caso fue abordado en trabajos anteriores (Masotta, 2012).

Lino murió unos meses después de la entrevista. Cuando regresé a la comunidad entregué a su familiares, copias del registro de "La matanza". Ellos lo recibieron pero no quisieron verlo por el poco tiempo transcurrido desde la desaparición del narrador.

El segundo episodio que comentaré se desarrolló en una comunidad del pueblo tapiete en la ciudad de Tartagal (provincia de Salta-Argentina). En el contexto del mismo proyecto de investigación lingüística del caso anterior propuse a un grupo de jóvenes la realización de un corto que documentara alguna práctica que ellos quisieran describir en su lengua materna. Luego de algunas reuniones orientadoras sobre las posibilidades del video y el uso de cámaras, el grupo decidió realizar una excursión a una zona boscosa en búsqueda de miel silvestre. Nos dirigimos al bosque y una vez encontrado un panal se encendió fuego para hacer humo y protegerse así de los ataques de las abejas. Con un hacha se derribó el árbol que contenía el panal y se recogió la miel en baldes. Luego, uno de ellos me relató pormenorizadamente en lengua tapiete lo que habían realizado con algunos comentarios reflexivos sobre esa práctica. Edité el material en Buenos Aires y regresé a la comunidad para mostrarlo. Los jóvenes acordaron con el resultado de la edición y se apuraron a preparar una presentación pública en la comunidad en un clima de festejo. Sin embargo, luego de la proyección se desarrolló una tensa y agitada discusión. Algunos hombres mayores, autoridades de la comunidad, impugnaron el video: allí no se mostraba la forma tradicional de la recolección de miel, y quienes habían participado no aparecían como verdaderos indígenas. La crítica a su vez fue contestada con criterios realistas. El debate fue largo y con múltiples argumentos de un lado y del otro. Por ejemplo, los mayores indicaban que la miel debía recogerse en cueros de conejo y no en baldes como mostraba el video. Además, el grupo que había realizado la recolección no estaba vestido a la usanza antigua sino con ropas urbanas (uno de ellos calzaba zapatos). En resumen, los mayores concluyeron que había que realizar otro registro recreando las formas antiguas. 
Para ello ejemplificaban con películas que habían visto en la televisión. Los jóvenes y algunos de sus familiares replicaban que ahora nadie (ni los mayores) recolectaba miel de esa manera e incluso no se usaba cuero de conejo pues ya no había esos animales en la zona.

La breve experiencia de video participativo indígena reverberó en los conflictos intergeneracionales de la comunidad a la vez que la colocó en un fuego cruzado entre las interpelaciones de la academia y de la televisión. Entre la mirada del realismo etnográfico y la de la ficción cinematográfica.

En ambos casos es evidente la acción de los informantes en el registro visual etnográfico. Los tiempos del cuerpo pasivo del informante ante la lente han quedado en el pasado (ya en la década del 1930 las mujeres caduveo le exigían dinero a Levi Strauss por el retrato que él hacia de sus tatuajes). Con todo, la acción involucrada trasciende los límites estrictos del documento visual pues se inscribe en las dinámicas sociales donde este se origina. En este sentido, tal vez lo más relevante no provenga de la documentación registrada en el campo sino del tipo de discusión en clave intercultural generada en torno al régimen de imágenes imperante.

La escalada de imágenes a nivel global abierta por el cambio tecnológico dobló la apuesta sobre su aparente neutralidad. A pesar de la abrumadora difusión y usos, la pregunta en clave antropológica e intercultural sobre quien necesita imágenes (y cuáles), no debería dejar de realizarse.

\section{Comentario final}

El temprano uso de fotografías en antropología desde el siglo XIX muestra el acento particular depositado en la observación. De todas las ciencias sociales es la que más conoció sobre de lentes, cámaras y emulsiones para revelar. La invención de la raza, las estéticas no occidentales y la diversidad cultural en general entraron en los engranajes de su pulsión escópica con una fuerza inédita desarrollada en su diferentes dimensiones: ver, hacer ver y hacerse ver. Sus efectos visuales fueron inmediatos. Se multiplicaron las expediciones, los museos, las publicaciones ilustradas. Los escenarios con grupos étnicos en las exposiciones internacionales y zoológicos metropolitanos (también llamados "jardines de aclimatación") fueron un punto singular de este proceso donde la mirada 
erudita y la curiosidad popular supieron encontrarse. He revisado documentación sobre algunos antropólogos que utilizaban esas ferias para la observación racial y cultural en Berlín y en Buenos Aires y es conocida la experiencia de Felix-Louis Regnault en Paris disparando su "fusil cronofotográfico" sobre una mujer wolof mientras confeccionaba una vasija de barro en la Exposición Etnográfica del África Occidental. Para algunos fue el origen mismo de la posteriormente llamada antropología visual. Desde entonces y hasta la actualidad el recurso a dispositivos de registro visual (fotografía, film o video) en la disciplina ha sido recurrente y se ha diversificado abordando y a veces superando los imperativos metodológicos y éticos que su incorporación ya planteaba en sus orígenes, en particular en investigaciones con sectores subalternos o comunidades indígenas. $\mathrm{Su}$ incorporación en el trabajo de campo y en la consecuente relación intercultural del antropólogo puede ser, además de una herramienta de registro, una piedra de toque para evaluar la experiencia de investigación.

Unos años atrás un consultante me presentaba en público con una expresión cargada de ironía: "él es antropólogo, viene a estudiarnos". Todos reían mientras yo intentaba modular inútilmente la crudeza de la expresión. Una vez más, lo que el humor ponía de manifiesto era algo que la interacción en el trabajo de campo tiende a ocultar. El desarrollo de las relaciones que el investigador produce en ese contexto oculta o, por lo menos tiende colocar en segundo plano los fines de investigación que lo motivan. Cortesía, hospitalidad o incluso amistad se sobreponen a esos fines. Esa presentación se parecía también a una advertencia sobre los riesgos de la presencia que una mirada especializada en la conducta social podría representar para el grupo. Buena parte de la etnografía se juega en ese contrapunto entre las observaciones de un antropólogo observado. Las imágenes y la visión no solo esta regimentadas en términos globales, estatales o metropolitanos sino también nativos y locales.

Tal vez lo mejor para contrarestar las ansiedades de esa condición sea atender a los objetivos del trabajo de campo previamente trazados con menos interés que a los desvíos inesperados que en él se dan con frecuencia cuando se cruzan ambas dimensiones. Jorge Preloran, uno de los iniciadores del film etnográfico en la Argentina, me explicó en una entrevista que sus documentales no eran resultado de un plan previo, sino de una experiencia de convivencia (aunque ese principio no aparece en todas sus películas). 
Creo que el acento de la metáfora de la etnografía como cuarto oscuro debe ponerse en el efecto de revelación antes que en de aislamiento. Una epifanía profana solo posible en la puesta en común de temporalidades diversas que el trabajo de campo puede conseguir si lo adopta como uno de sus principales esfuerzos.

A una de las primeras maestras del pueblo wichi se le solicitó que realice algunos dibujos sobre la creencia tradicional en un ser sobrenatural que al invocársele surgía desde debajo de la tierra para curar enfermos. Ella aceptó y lo dibujó de espalda. Al preguntarle por qué no mostraba su rostro me explicó: "Es muy poderoso y nadie se atreve a verlo de frente".

Las imágenes pueden ser una buena fuente de revelación de conocimiento en antropología si a la vez se evalúa su relación con el régimen escópico vigente y se hace ingresar en él la discusión pertinente desde el punto de vista local.

\section{Referencias}

CLIFFORD, J. y MARCUS, G. Writing Culture: The poetics and Politics of Etnography. Berkeley and Los Angeles: University of California Press, 1986.

CLIFFORD J. The Predicamento of Culture: Twentieth-Century Ethnography, Literature, and Art. Cambridge: Harvard University Press, 1988.

EVANS-PRITCHARD, E. Los Nuer. Barcelona: Anagrama, 1977. GEERTZ, C. El antropólogo como autor. Buenos Aires: Paidós, 1989. GRIAULE, M. El Método de la etnografía. Buenos Aires: Nova, 1957. JAY, M. "Regímenes escópicos de la modernidad". En: MARTÍN, Jay. Campos de Fuerza. Buenos Aires: Paidós, 2003.

MASOTTA, C. "La matanza". Memoria y poética de la transmisión.”. En: Revista Corpus, Tomo I número 3. Archivos virtuales de la alteridad americana. Disponible a partir de: http://ppct.caicyt.gov.ar/index.php/corpus/index.

PINNEY, C. "The Parallel histories of anthropology and photography". En:

EDWARDS, Elizabeth (ed.), Anthropology and Photography. 1860-1920. New Haven and London: Yale University Press and The Royal Anthropological Institute, 1992. REVISTA DOMUS. Mission Dakar-Djibouti. Rozzano: Imprese di Milano, 2012. Disponível em: http://www.domusweb.it/en/art/mission-dakar-djibouti/.

ROSALDO, R. "From. the. door. of. his. Tent: The. fieldworker. and. the. Inquisitor". En: CLIFFORD, J. y MARCUS G. Writing Culture: The poetics and Politics of Etnography. Berkeley and Los Angeles: University of California Press, 1986.

Recebido em: 21/11/2012

Aprovado em: 24/01/2013 